\title{
Myocardial bridging as a cause of acute myocardial infarction: a case report
}

\author{
Ramazan Akdemir*1, Huseyin Gunduz ${ }^{2}$, Yunus Emiroglu ${ }^{3}$ and \\ Cihangir Uyan ${ }^{2}$
}

Address: ${ }^{1}$ Department of Cardiology, Düzce Medical School, Abant Izzet Baysal University, Düzce, Turkey, ${ }^{2}$ Department of Cardiology, Izzet Baysal Medical School, Abant Izzet Baysal University, Bolu, Turkey and ${ }^{3}$ Department of Cardiology, Kosuyolu Heart-Education and Research Hospital, Istanbul, Turkey

E-mail: Ramazan Akdemir* -rakdemir@yahoo.com; Huseyin Gunduz - drhuseyingunduz@yahoo.com; Yunus Emiroglu - yemiroglu@yahoo.com; Cihangir Uyan - cihangirayten@superonline.com

${ }^{*}$ Corresponding author

Published: 2I September 2002

BMC Cardiovascular Disorders 2002, 2:15
Received: 6 March 2002

Accepted: 21 September 2002

This article is available from: http://www.biomedcentral.com/|47/-226I/2//5

(C) 2002 Akdemir et al; licensee BioMed Central Ltd. This article is published in Open Access: verbatim copying and redistribution of this article are permitted in all media for any purpose, provided this notice is preserved along with the article's original URL.

Keywords: Myocardial bridging, myocardial infarction, blood donation, anemia, angiography

\begin{abstract}
Background: Systolic compression of a coronary artery by overlying myocardial tissue is termed myocardial bridging. Myocardial bridging usually has a benign prognosis, but some cases resulting in myocardial ischemia, infarction and sudden cardiac death have been reported. We are reporting a case of myocardial bridging which was complicated with acute myocardial infarction associated with inappropriate blood donation.
\end{abstract}

Case presentation: A 33 year-old-man was admitted to our emergency with acute anteroseptal myocardial infarction after a blood donation. The electrocardiography showed sinus rhythm and was consistent with an acute anteroseptal myocardial infarction. We decided to perform primary percutanous intervention ( $\mathrm{PCl}$ ). Myocardial bridging was observed in the mid segment of the left anterior descending coronary artery on coronary angiogram. $\mathrm{PCl}$ was canceled and medical follow up was decided. Blood transfusion was made because he had a deep anemia. A normal hemaglobin level and clinical reperfusion was achieved after ten hours by blood transfusion. At the one year follow up visit, our patient was healthy and had no cardiac complaints.

Conclusions: Myocardial bridging may cause acute myocardial infarction in various clinical conditions. Although the condition in this case caused profound anemia related acute myocardial infarction, its treatment and management was unusual.

\section{Background}

The major coronary arteries are located in the sub-epicardial region [1]. Localization of a coronary arterial segment in the myocardial tissue is termed myocardial bridging. In these patients, there is a temporary systolic coronary arte- rial luminal narrowing. Symptomatic patients are most often middle-aged men with typical or atypical chest pain, either related or unrelated to exercise [1-3]. Myocardial bridging usually has a benign prognosis, but some cases 


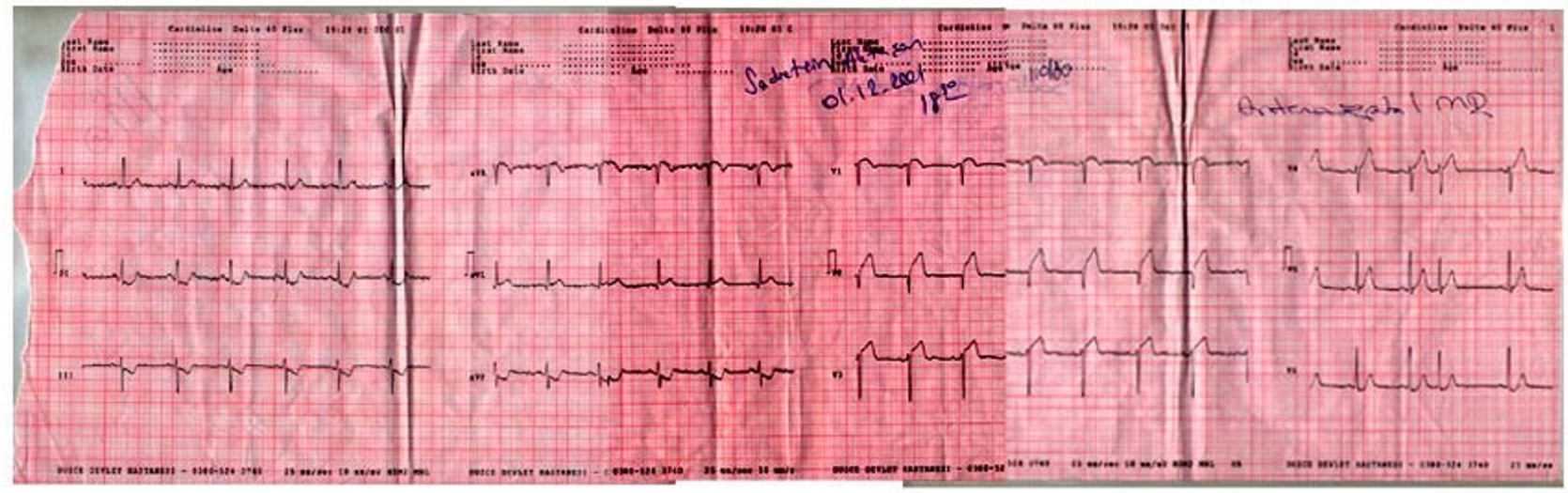

\section{Figure I}

ECG shows acute anteroseptal wall myocardial infarction.

associated with myocardial ischemia, infarction, and sudden death have been reported [1-5].

\section{Case presentation}

A 33 year-old-man was admitted to our emergency department complaining of 5 hours of severe crushing chest pain. He had smoking history as a risk factor for coronary artery disease and had had atypical chest pain for two years. He had also made blood donations of about ten units within the last two years. His chest pain had started after the completion of the most recent blood donation in a health center. On physical examination, paleness and cold sweating were noted. His systolic and diastolic blood pressures were 110 and $80 \mathrm{mmHg}$ respectively, and his heart rate was $90 /$ minute.

The electrocardiography showed sinus rhythm, and was consistent with an acute anteroseptal myocardial infarction (above $2 \mathrm{~mm}$ ST elevation anterior V1-V4 precordial leads) and reciprocal ST depressions in DII, DIII and aVF (figure. 1). He was given: oral acetylsalicylic acid, $300 \mathrm{mg}$ per day; $5000 \mathrm{U}$ bolus standard heparin, $1000 \mathrm{U}$ /hour infusion; metoprolol, $5 \mathrm{mg}$ per day; and nytroglicerin infusion, $10 \mu \mathrm{g} / \mathrm{minute}$. At the same time, blood tests were carried out. Cardiac troponin and myoglobin were slightly elevated, but CK-MB was within normal limits.

We decided to perform primary percutanous intervention (PCI). Coronary angiography and left ventriculography were performed. The left coronary system was imaged at left and right oblique, right cranial and caudal and anteroposterior cranial positions. Significant coronary artery systolic luminal narrowing was observed in the mid segment of the left anterior descending coronary artery at left anterior oblique cranial position on coronary angiogram. (figure 2 and figure 3 ). The right coronary artery was nor- mal. The left ventricular angiography showed apical and antero-lateral hypokinesia. PCI was cancelled and medical follow up was decided.

The patient was transferred to coronary care unit for medical treatment. Since his hemoglobin level was $6 \mathrm{mg} / \mathrm{dl}$, a blood sample was drawn to investigate the cause of this profound anemia. Hemathologic investigation concluded that the only cause of this profound anemia was excessive and inappropriate blood donation. Two units of package cell were given to the patient within three hours, and a further four units of package cell were given after six hours. A normal hemaglobin level was achieved after ten hours. Three hours after the patient being admitted to the emergency department, his chest pain had completely disappeared, ST elevations had come to an isoelectric line and frequent ventricular extra-systoles were observed on the monitor. Myocardial enzyme values taken after twentyfour hours were elevated to a level three times greater than normal. At the one year follow up visit, our patient was healthy and had no cardiac complaints.

\section{Discussion}

Myocardial bridging can be seen as an incidental finding at coronary arteriography. Previous studies have reported its prevalence at 0.5 to $33 \%$ of all cases [6]. Myocardial bridging rarely causes myocardial ischemia [7]. Also, it is often considered as a simple variant of the normal anatomy of coronary arteries. But previous reports have demonstrated its pathologic potential. Stable or unstable angina pectoris, acute myocardial infarction, complete atrioventricular block or sudden death associated with myocardial bridges have been described $[8,9]$.

It is well known that the main pathogenesis of acute coronary syndromes consists of atherosclerotic plaque dis- 


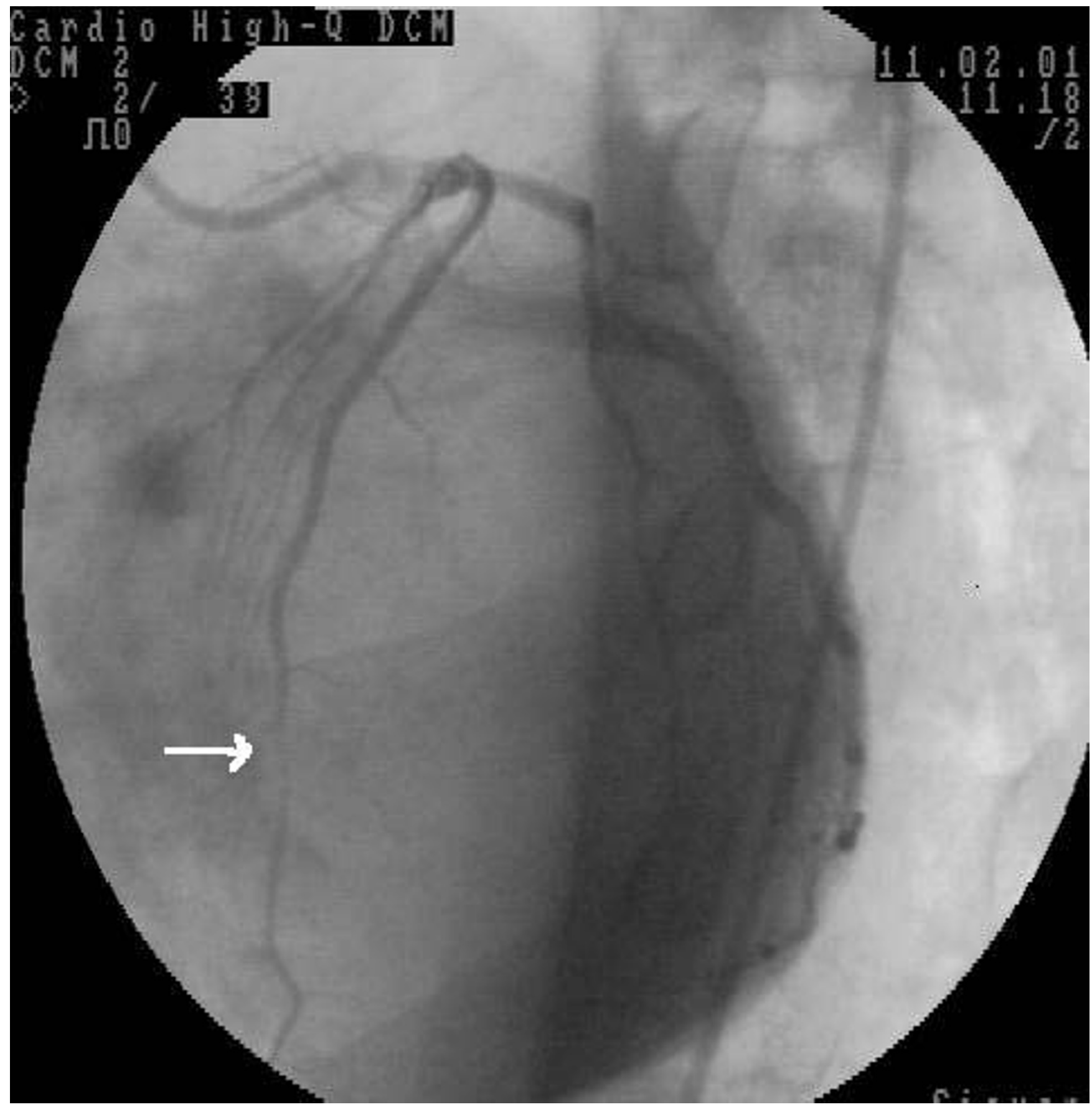

\section{Figure 2}

Systolic compression at the mid-portion of LAD at the LAO view.

ruption and thrombus formation [10]. However, in muscular bridging there is a temporary coronary luminal narrowing. If a patient has a endothelial injury, acute myocardial infartion may occur. Our patient had a smoking history, and nicotine could have damaged the endothelial structure at the bridged segment. Possible explanation of
AMI in our patient could be endothelial injury, severe coronary spasm and finally thrombotic occlusion [11].

Primary percutanous revascularization was planned. However, no atherosclerotic plaque in the major coronary arteries was detected on coronary angiography. There was temporary systolic coronary arterial luminal narrowing at 


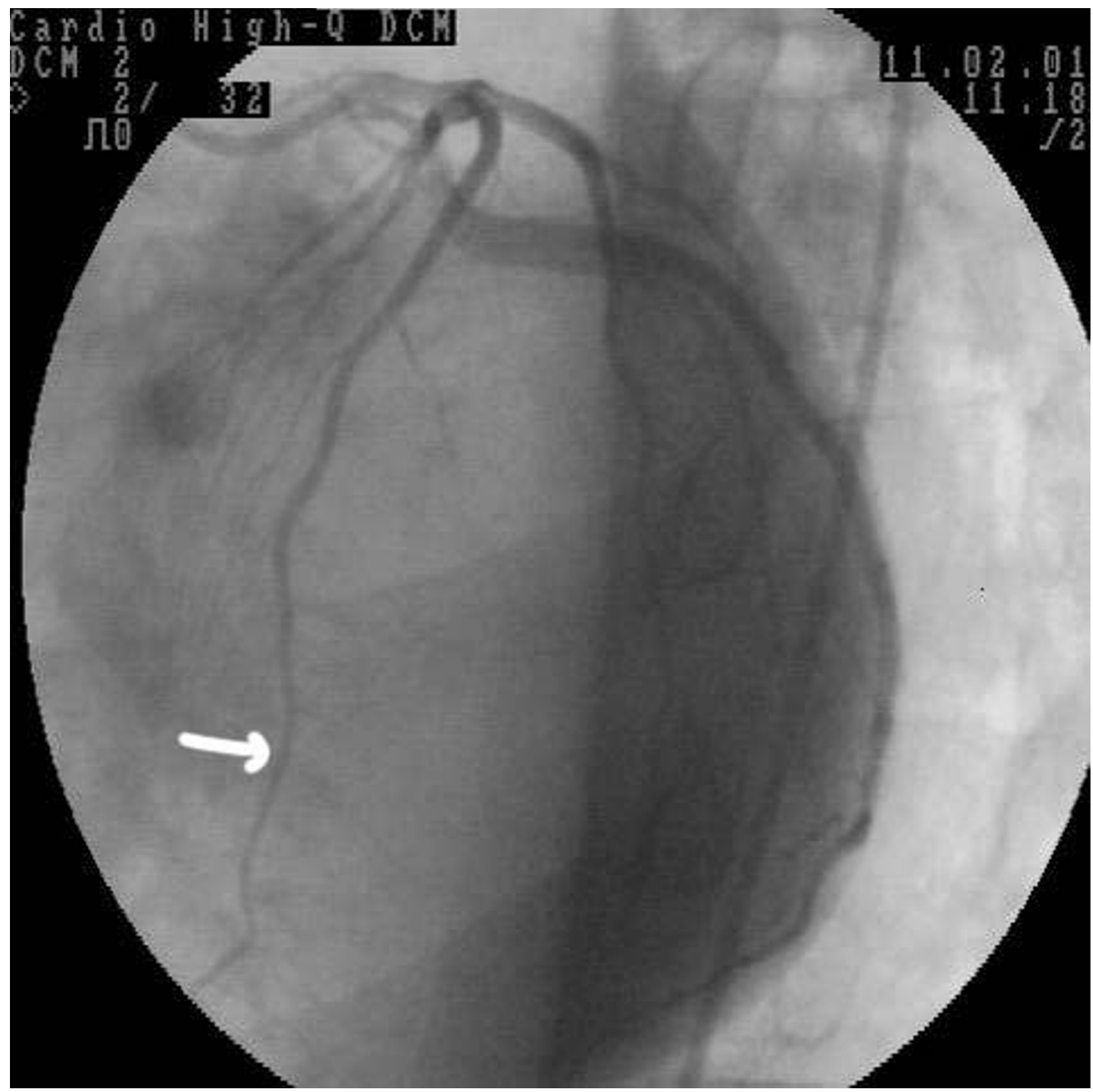

Figure 3

Normalization of the systolic compression at the mid-portion of LAD

the mid-portion of LAD at LAO view. Therefore, we decided to follow the patient conservatively. We obtained an excellent result with blood transfusion. This is a case of acute myocardial infarction caused by coronary thrombosis in the setting of myocardial bridging. A possible association between myocardial bridging and acute myocardial infarction following excess blood donation could not be excluded. This is a report of a case of acute ischemic complication related to myocardial bridging of the LAD, which was resolved by appropriate blood transfusion, and acetylsalicilic acid, beta-blocker, nytroglicerin.

\section{Conclusions}

Myocardial bridging may cause acute myocardial infarction in various clinical conditions. Although the condition in this case caused profound anemia related acute 
myocardial infarction, its treatment and management was unusual. This report, together with those previously published, suggests that myocardial bridging may no longer be considered simply a benign variation of coronary anatomy.

\section{Competing Interest}

None declared

\section{Authors' contributions}

1-Ramazan Akdemir: Wrote the manuscript.

2-Huseyin Gunduz: Followed the patients after discharge from the hospital.

3-Yunus Emiroglu: Made echocardiography.

4-Cihangir Uyan: Made coronary angiography.

\section{Acknowledgements}

Written consent was obtained from the patient for publication of the patient's details.

\section{References}

I. Bestetti RB, Costa RS, Zucolotto S, et al: Fatal outcome associated with autopsy-proven myocardial bridging of the left anterior descending coronary artery. Eur Heart J 1989, 10:573-576

2. Juillière $\mathrm{Y}$, Berder $\mathrm{V}$, Sutti-Selton $\mathrm{CH}$, et al: Isolated myocardial bridges with angiographic milking of the left anterior descending coronary artery: a long-term follow-up study. Am Heart J 1995, 129:663-665

3. Tio RA, Van Gelder IC, Boonstra PW, et al: Myocardial bridging in a survivor of sudden cardiac near-death: role of intracoronary doppler flow measurements and angiography during dobutamine stress in the clinical evaluation. Heart 1997, 77:280-282

4. Agirbasli M, Martin GS, Stout JB, et al: Myocardial bridge as a cause of thrombus formation and myocardial infarction in a young athlete. Clin Cardiol 1997, 20: I032-1036

5. Cutler D, Wallace JM: Myocardial bridging in a young patient with sudden death. Clin Cardiol 1997, 20:581-583

6. Irvin RG: The angiographic prevalence of myocardial bridging in man. Chest 1982, 81:198-202

7. Ferreira AG Jr, Trotter SE, Konig B Jr, et al: Myocardial bridges: morphological and functional aspects. Br Heart J I99I, 66:364367

8. Chambers JD Jr, Johns JP, Berndt TB, et al: Myocardial stunning resulting from systolic coronary artery compression by myocardial bridging. Am Heart J 1994, I 28:1036-1038

9. Den Dulk K, Brugada P, Braat $\mathrm{S}$, et al: Myocardial bridging as a cause of paroxysmal atrioventricular block. J Am Coll Cardiol 1983, 1965:969

10. Ridolfi RL, Hutchins GM: The relationship between the coronary lesions and myocardial infarct, ulceration of atherosclerotic plaques precipitating coronary thrombosis. Am Heart J 1977, 93:468-86

II. Bauters C MD, Chmait A MD, Tricot O MD, Lamblin N MD, Belle EV MD, Lablanche JM MD: Coronary Thrombosis and Myocardial Bridging, Circulation 2002, 105:130

\section{Pre-publication history}

The pre-publication history for this paper can be accessed here:

http://www.biomedcentral.com/1471-2261/2/15/prepub

\footnotetext{
Publish with BioMed Central and every scientist can read your work free of charge

"BioMedcentral will be the most significant development for disseminating the results of biomedical research in our lifetime."

$$
\text { Paul Nurse, Director-General, Imperial Cancer Research Fund }
$$

Publish with BMC and your research papers will be:

- available free of charge to the entire biomedical community

- peer reviewed and published immediately upon acceptance

- cited in PubMed and archived on PubMed Central

- yours - you keep the copyright 